\title{
A New Process for Separation of p-Xylene*
}

\author{
by Tozo Amemiya**, Yoshio Hatanaka*** and Tamotsu Nakamura****
}

\begin{abstract}
Summary: Maruzen Oil has developed an economical direct-cooling process for p-xylene production. Material of $99.5 \%$ purity can be produced at a cost of $4.5 \mathrm{e} / \mathrm{lb}$. Recovery of aromatics in the feed is almost $100 \mathrm{~mol} \%$. Ethylene gas and liquid are directly contacted with the xylene mixture to cool and crystallize the p-xylene. Metallurgy requirements are mild. The process is easy to operate.
\end{abstract}

Maruzen Oil has been producing p-xylene by crystallization since 1960. A third-generation plant has been in operation for more than 3 years.

\section{Introduction}

$P$-xylene (PX) has been supplied from the separation of $\mathrm{C}_{8}$ aromatics mixture and synthetic route have not been practised. There are variety of $p$-xylene separation processes in operation but they may be classified into three groups.

(1) Crystallization Maruzen, Chevron, AMO-

CO, ARCO, Phillips, KRUPP, Esso

(2) Adsorption UOP, Toray

(3) Complex Formation MGG

Maruzen Oil has been producing p-xylene by crystallization since 1960 , and the third generation plant has been in operation for more than three years. This Maruzen $p$-xylene process "XIS Process" consists of two units. The first unit, XS unit, separates $p$-xylene from the xylene mixture by the deep-freezing crystallization method using ethylene as a coolant. The second unit, XI unit, isomerizes $p$-xylene lean raffinate into equilibrium xylenes in the presence of the silica alumina type catalyst.

\section{Concept of Crystallization}

$\mathrm{C}_{8}$ aromatics consist of four isomers $p$-xylene, $o$-xylene, $m$-xylene and ethylbenzene. Physical boiling and melting points of these four isomers are given in Table 1. Their boiling points are so close that it is difficult to separate each isomer by fractionation. Ethylbenzene boils at $2.17^{\circ} \mathrm{C}$ lower than $p$-xylene and can be separated by super fractionation. This is a common practise in the

\footnotetext{
* Received December 13, 1973

** Maruzen Oil Co., Ltd. (5-3, 1-chome, Ohtemachi, Chiyoda-ku, Tokyo 100)

*** Maruzen Oil of U.S.A., Inc. (641 Lexington Avenue, New York, N. Y. 10022)

**** Technical Planning Dept., Maruzen Oil Co., Ltd. (3, 1-chome, Nagahoribashi-suji, Minami$\mathrm{ku}$, Osaka 542)
}

industry. $O$-xylene has the highest boiling point and also can be separated by distillation.

However, $p$-xylene and $m$-xylene boil so close each other: that is less than one degree centigrade. It is impossible to separate them by fractionation economically. But $p$-xylene has the highest melting point of $13.26^{\circ} \mathrm{C}$, which is 38.4 ${ }^{\circ} \mathrm{C}$ higher than the closest isomer 0 -xylene. Therefore, crystallization separation may be used to separate $p$-xylene from the xylene mixture.

Since a xylene mixture can be considered as an ideal solution'1) with respect to solid-liquid equilibrium, the primary crystallization points

Table 1 The Physical Properties of Xylene Isomers

\begin{tabular}{l|c|c}
\hline & $\begin{array}{c}\text { Boiling Point }\left({ }^{\circ} \mathrm{C}\right) \\
\text { at } 760 \mathrm{mmHg}\end{array}$ & $\begin{array}{c}\text { Melting Point } \\
\left({ }^{\circ} \mathrm{C}\right)\end{array}$ \\
\hline o-Xylene & 144.411 & -25.182 \\
m-Xylene & 139.103 & -47.872 \\
$p$-Xylene & 138.351 & 13.263 \\
Ethylbenzene & 136.186 & -94.975 \\
\hline
\end{tabular}

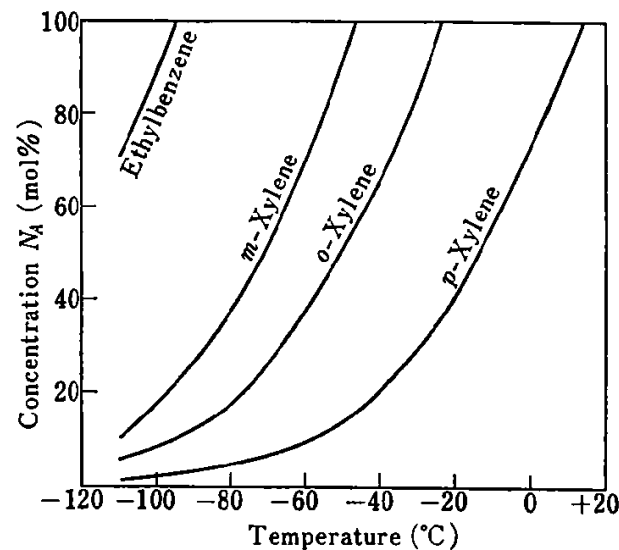

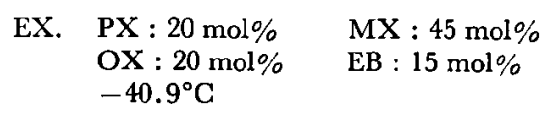

Fig. 1 Solubility-Temperature Relationship of $\mathrm{C}_{8}$ Aromatics 


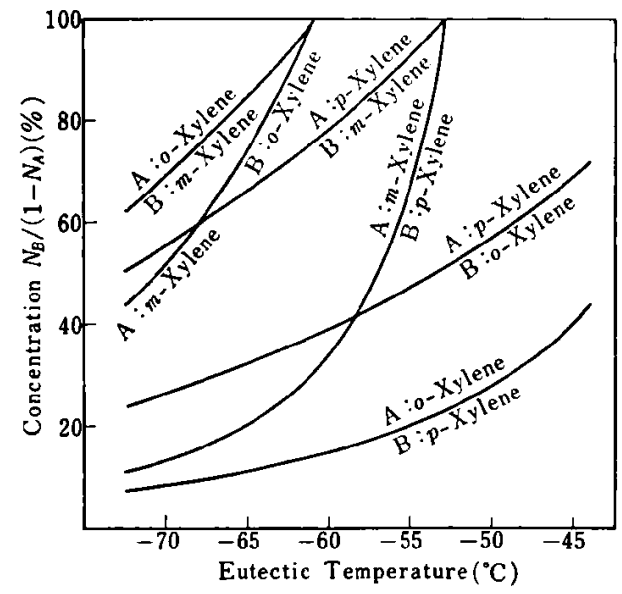

EX. MX: $\frac{45}{100-20} \times 100=56.25 \mathrm{~mol} \%$

OX : $\frac{20}{100-20} \times 100=25.00 \mathrm{~mol} \%$

$\mathrm{EB}: \frac{15}{100-20} \times 100=18.75 \mathrm{~mol}^{\circ}$ 。

$-69.8^{\circ} \mathrm{C}$

$\mathrm{PX}: 6.4 \mathrm{~mol} \% \quad \mathrm{MX}: 52.7 \mathrm{~mol} \%$

OX : $23.4 \mathrm{~mol}^{\circ} \circ \quad$ EB : $17.6 \mathrm{~mol} \%$

Fig. 2 Eutectic Temperature vs. Composition of $\mathrm{C}_{8}$ Aromatics

and the eutectic points may be easily calculated for the known xylene composition.

Fig. 1 shows solubility curves for xylene isomers in the $\mathrm{C}_{8}$ aromatics solution. This is a straight forward thermodynamic relationship. For example, the primary crystallization point in the mixture of $p$-xylene $20 \mathrm{~mol} \%$, o-xylene $20 \mathrm{~mol} \%$, $m$-xylene $45 \mathrm{~mol} \%$ and ethylbenzene $15 \mathrm{~mol} \%$ is $-40.9^{\circ} \mathrm{C}$ and $p$-xylene starts to crystallize out. As the temperature further goes down, more $p$ xylene crystals continue to form and liquid phase becomes lean in $p$-xylene until the binary eutectic point is reached.

Fig. 2 shows the binary eutectic curves in $\mathrm{C}_{8}$ aromatics solution. As for example, the abovementioned mixture of $p$-xylene 20, o-xylene 20, $m$-xylene 45 and ethylbenzene $15 \mathrm{~mol} \%$ may be considered, if one assumes that all $p$-xylene is taken out of the mixture, the composition of the remaining mixture becomes 0 -xylene $25.00 \mathrm{~mol} \%$, $m$-xylene $56.25 \mathrm{~mol}^{\circ}$ and ethylbenzene 18.75 $\mathrm{mol} \%$. This is of course a hypothetic procedure, because, before $p$-xylene content approaches to zero, binary and tertiary eutectic crystal will deposit out. But curves in Fig. 2 and Fig. 3 are adjusted to such hypothetic procedure. Therefore, one can read out the binary cutcctic points: $-69.8^{\circ} \mathrm{C}$ for $p$-xylene and $m$-xylene and -71.8 ${ }^{\circ} \mathrm{C}$ for $p$-xylene and $o$-xylene. The $p$-xylene-

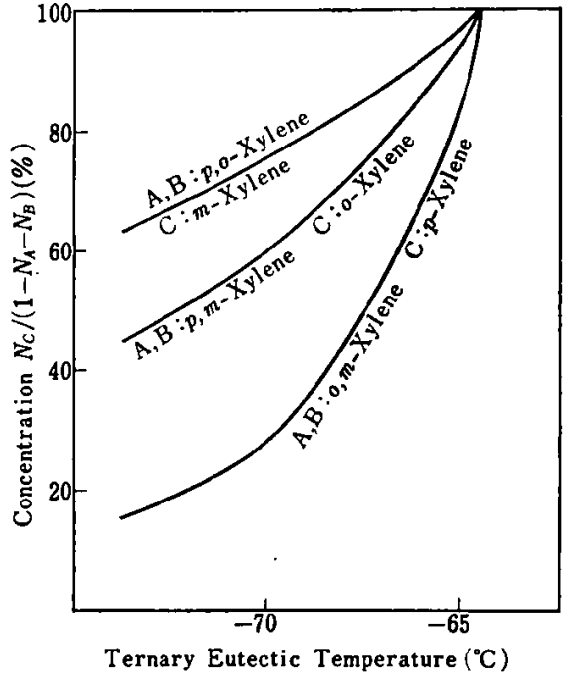

EX.

$$
\begin{aligned}
& \mathrm{OX}: \frac{20}{100-20-45} \times 100=57.14 \mathrm{~mol} \% \\
& \mathrm{~EB}: \frac{15}{100-20-45} \times 100=42.85 \mathrm{~mol} \% \\
& -70.8^{\circ} \mathrm{C}
\end{aligned}
$$

Fig. 3 Ternary Eutectic Temperature vs. Composition of $\mathrm{C}_{\mathbf{8}}$ Aromatics

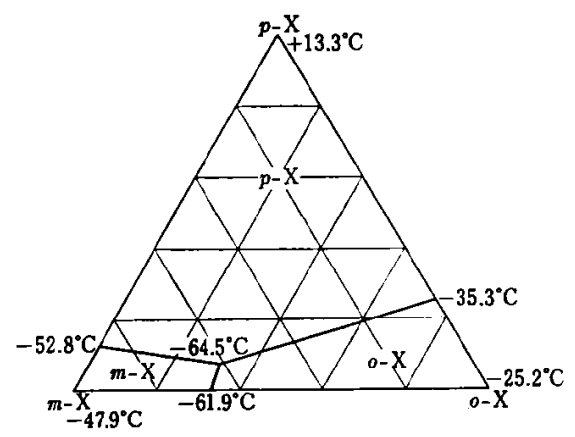

Fig. 4 Ternary Phase Diagram

$m$-xylene eutectoid starts to crystallize out as secondly crystal at $-69.8^{\circ} \mathrm{C}$. In our actual operation we saturate xylenes with ethylene so that the binary eutectic point is reduced by approximately one degree centigrade. Fig. 3 shows ternary eutectic curves and for the same example ternary eutectic crystal will form at $-70.8^{\circ} \mathrm{C}$.

The primary crystallization points and eutectic points can be calculated from solubility data, and a ternary phase diagram can be determined as shown in Fig. 4.

These calculations can be extended to the quaternary system including $0-, m$ - and $p$-xylenes, and ethylbenzene. The quaternary phase diagram thus obtained can not be shown on a plane, so only the range in which $p$-xylene crystallizes out as primary crystal is projected on a plane perpendicular to the temperature axis, as 
shown in Fig. 5.

Solubility of ethylene in xylene mixture is shown in Fig. 6 and Fgi. 7.

\section{Outline of Maruzen p-Xylene Process (XIS Process)}

Maruzen Oil has developed direct-cooling process, where ethylene gas and liquid are directly contacted with the xylene mixture to cool and crystallize the $p$-xylene. Fig. 8 shows the entire separation system which consists of five sections.

The first section is a superfractionation unit where ethylbenzene and o-xylene are separated as products, though 0 -xylene production is an

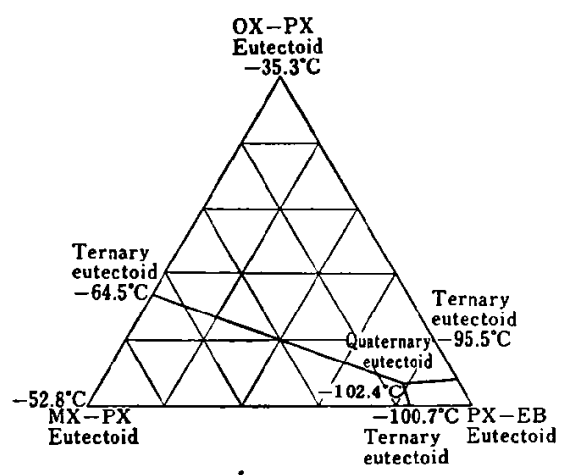

Fig. 5 Quaternary Phase Diagram

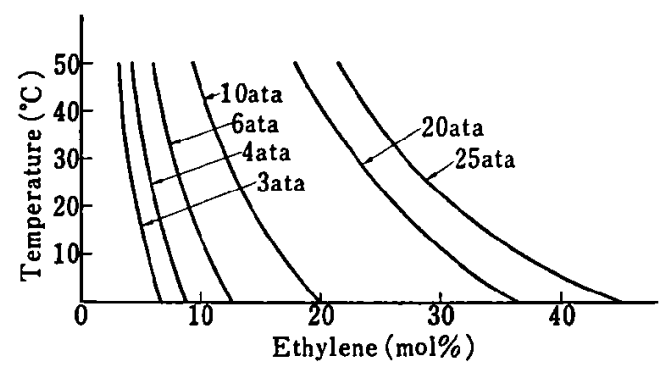

Fig. 6 Solubility of Ethylene in Xylene Mixture (High temp. and high press.) option. The remainder, which includes $m$-xylene, $p$-xylene and some of both ethylbenzene and $o$ xylene, is fed to the crystallization separation unit, in which $p$-xylene is separated. The third section is a refrigeration unit, where gaseous and liquid ethylene are provided as a coolant for the $p$-xylene separation unit. The fourth section is an isomerization unit. The last section is a clean up unit for isomerized xylene and other byproducts such as benzene, toluene and heavy aromatics plus some light gases.

\subsection{Superfractionation (SFX)}

The feed to this superfractionation unit is cracked naphtha and reformate xylenes plus isomerized recycle. The main superfractionator has 350 trays or more and is operated at the reflux ratio as high as 50 or more. Ethylbenzene and oxylene are taken out as products and remaining mixture goes to $p$-xylene separation unit.

\section{$3.2 p-X y l e n e$ Separation (XS)}

Fig. 9 shows the flow of the direct cooling system in which ethylene is introduced directly into the xylene mixture. Xylenes from the superfractionation and isomerization units are pumped into

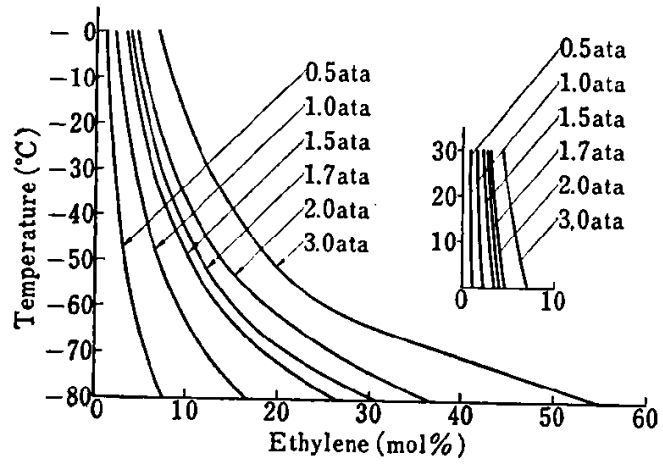

Fig. 7 Solubility of Ethylene in Xylene Mixture (Low temp. and low press.)

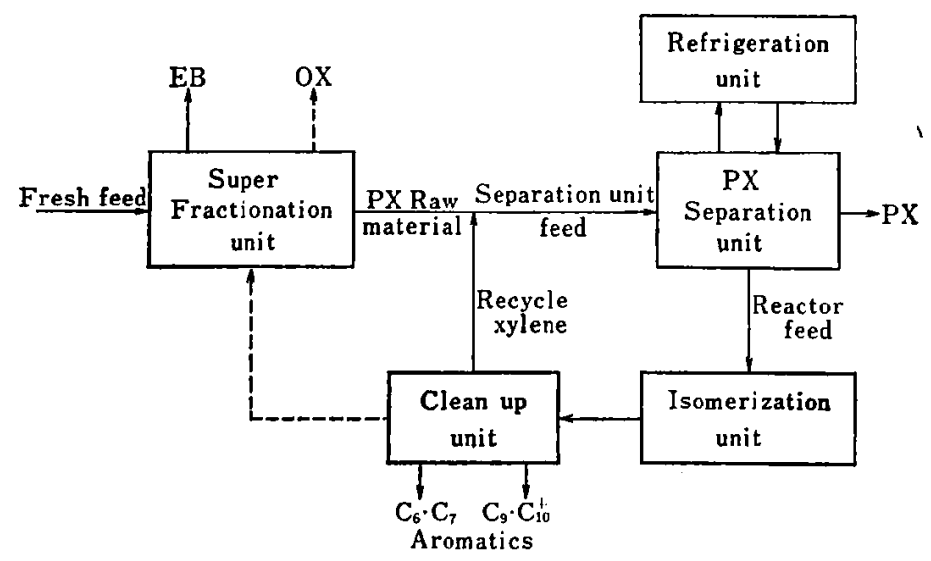

Fig. 8 Flow Diagram 


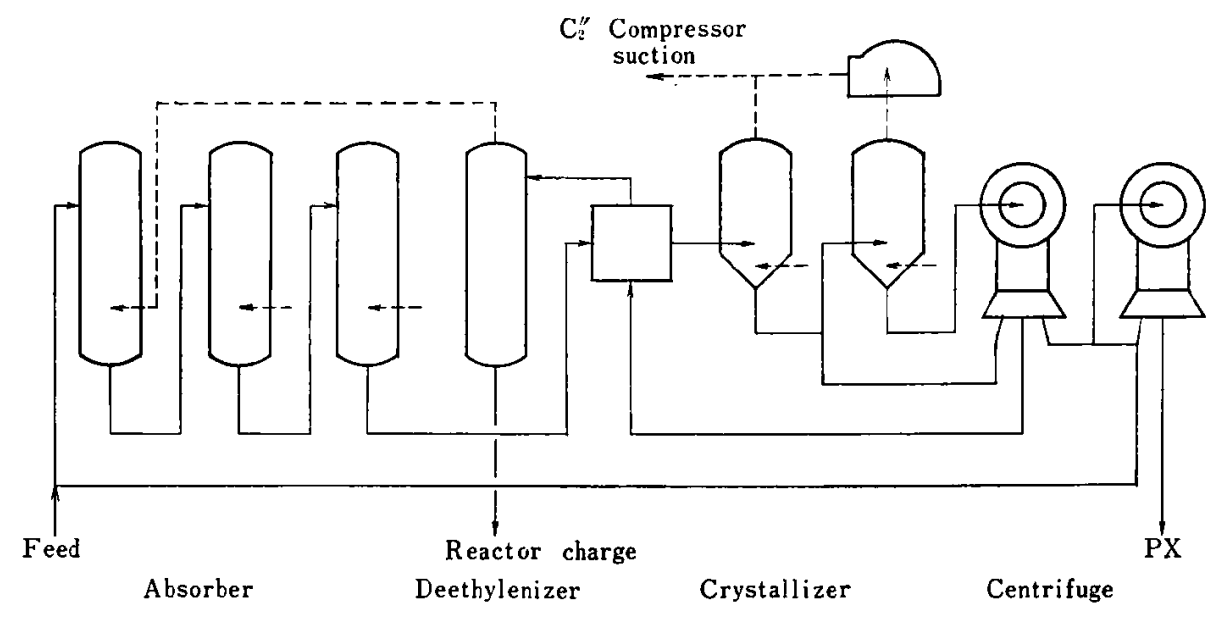

Fig. 9 PX Separation Unit

the first-stage absorber, to which gascous ethylene from the deethylenizer column is introduced. In the second-stage absorber, gaseous ethylene from an intermediate compression stage is introduced. The third-stage absorber receives ethylene gas from the final gas-compression stage. All absorbers are operated at a constant temperature of $20^{\circ} \mathrm{C}$. Since ethylene absorption into xylene is exothermic, cooling system is provided so as to remove the heat of absorption and to maintain constant temperature. We believe it is more economical to let ethylene be absorbed into xylene in step. Side streams are taken from various ethylene compression stages. Ethylene-saturated xylenes are then cooled by heat exchange with mother liquor from the crystal-separation centrifuge. And the mixture goes to No. 1 crystallizer at $-50^{\circ} \mathrm{C}$. Two crystallizers are operated in series. Operating temperatures at No. 1 and No. 2 crystallizers are approximately $-60^{\circ} \mathrm{C}$ and $-70^{\circ} \mathrm{C}$, respectively. Liquid ethylene is added to both crystallizers and most of ethylene is permitted to vaporize in order to cool xylene mixture and to crystallize $p$-xylene. $P$-xylene crystal forms continuously and the mixture becomes a slurry. This slurry, which is mixture of $p$-xylene crystal, liquid xylenes and desolved ethylene, goes to the first centrifuge and is split at the temperature slightly higher than the eutectic point into three parts; solid, screen effluent and mother liquor. The purity of solid is $85 \sim 95 \%$ depending upon its crystal size and the type of the separator used. Crude $p$-xylene crystal is permitted to partially melt and sent to the second centrifuge directly. After the second centrifuge $p$-xylene becomes final product. Purity is $99.5 \%$ or better.

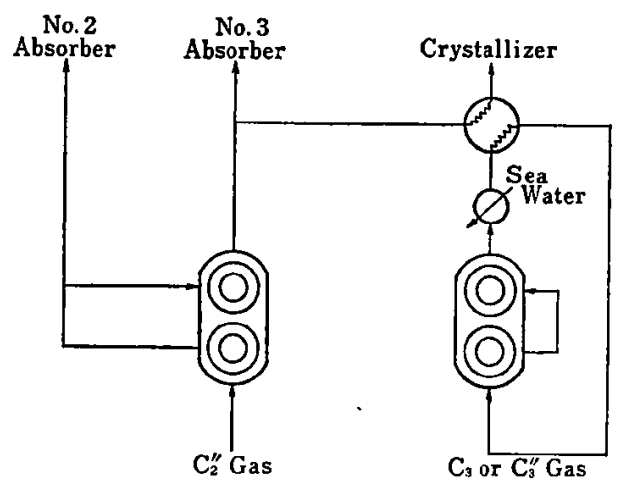

Fig. 10 Refrigeration Unit

Fig. 10 shows refrigeration unit. This is a service unit to $p$-xylene separation unit. To the second and third stage absorbers, ethylene from the first and second stage side streams of the compressor is added respectively. The remainder of the compressed ethylene gas is liquefied in the cascade-condenser in contact with liquid propane or propylene. Propane or propylene is also compressed and liquefied in contact with cooling water.

\subsection{Isomerization (XI)}

The equilibrium composition') of $\mathrm{C}_{8}$ aromatics over the wide range of temperature is given in Fig. 11. $P$-xylene is separated from the equilibrium mixture. This nonequilibrium $p$-xylene lean mixture from the crystallization process is easily converted to a $p$-xylene rich equilibrium mixture by silica alumina catalyst, which has been developed by Maruzen Oil. The flow of the XI unit is shown in Fig. 12. The nonequilibrium $p$-xylene lean mixture from the first centrifuge filtrate is passed through a silica alumina type catalyst fixed bed of high selectivity 
and high efficiency to obtain an equilibrium xylene mixture. Isomerization reaction takes place in the vapor phase under the atmospheric pressure and at $410 \sim 510^{\circ} \mathrm{C}$ in the presence of steam. Other side reactions such as disproportionation of xylene and dealkylation of ethylbenzene are controlled to a satisfactory degree.

A non-noble metal type silica alumina catalyst is much less expensive than a noble metal type

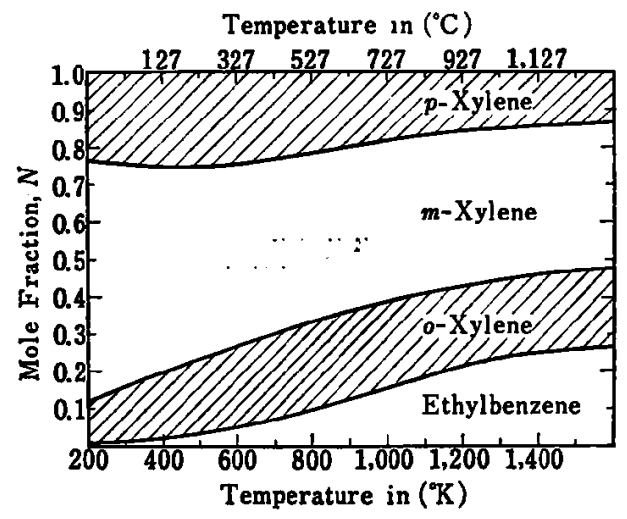

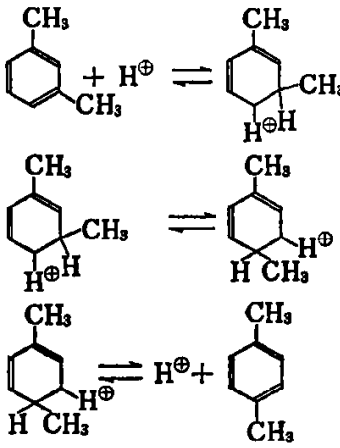

Fig. 11 Equilibrium Concentration of $\mathrm{C}_{8}$ Aromatics catalyst. The expected life of the catalyst is longer than two years and can be easily regenerated by air.

Since we do not use hydrogen, no naphthenic hydrocarbons are produced. Moreover the process does not require hydrogen compressor, which contributes to lower investment. Therefore, the recovery of aromatics in feed are almost $100 \%$ on molar basis. Metallurgy requirements are mild. The process is easy to operate. The isomerized mixture is sent to the clean up fractionator as the feed.

The small amount of the gaseous by-products and light aromatics are separated from the top of the first column. The isomerized xylene and heavy aromatics are obtained from the top and the bottom of the second column, respectively. The product, xylene, is recycled to the XS unit. The gaseous product is used as fuel. The light and heavy aromatics may be used in a variety of uses, such as solvents, feeds for benzene and

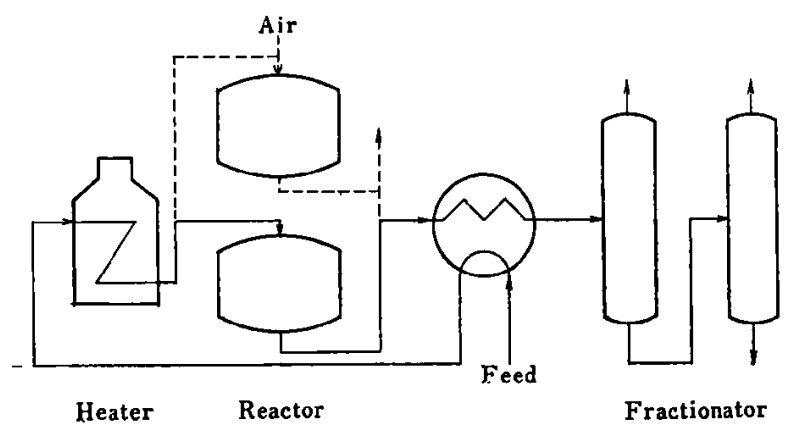

Fig. 12 Isomerization Unit

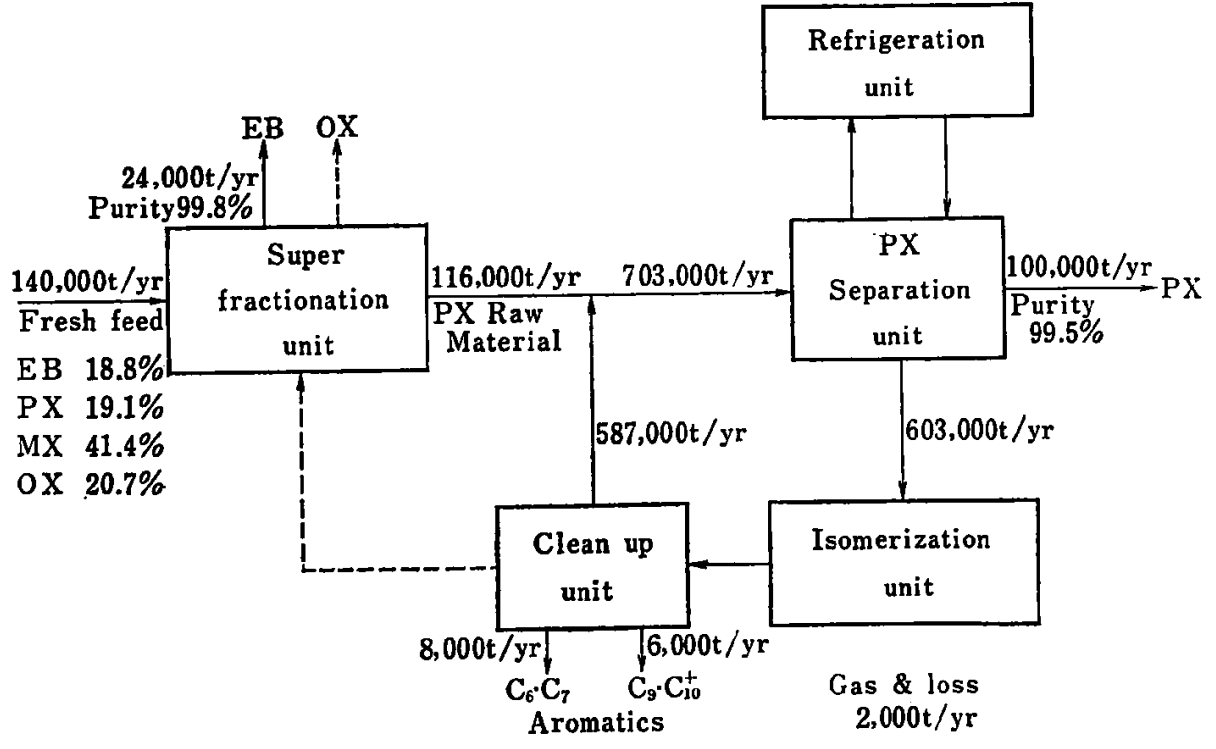

Fig. 13 Material Balance 
toluene recovery and pseudocumene and durene production.

\section{Material Balance and Production Cost of p-Xylene}

As a summary of Maruzen Process, material balance is shown in Fig. 13, which is based on $p$ xylene $100,000 \mathrm{t} / \mathrm{yr}$ plant. For this material balance a typical reformate xylene is taken as a feed stock. Products are $p$-xylene 100,000 t/yr with the purity of $99.5 \%$ and ethylbenzene 24,000 $\mathrm{t} / \mathrm{yr}$ with the purity of $99.8 \%$. In this case $o$-xylene is not produced but 0 -xylene may be produced if it is desirable. A total feed is 140,000 $\mathrm{t} / \mathrm{yr}$ which is little for such quantities of $p$-xylene and ethylbenzene production. This is due to little gas and loss of 2,000 t/yr which is less than $2 \%$ of total feed. Another advantage to be pointed out is that the yield of liquid by-product is as low as $14,000 \mathrm{t} / \mathrm{yr}$. Moreover, this is practically pure aromatics and it is ready to be marketed either as gasoline blenders or aromatic solvents. In addition, the recycle volume is relatively low, a little over five times the feed. This small quantity of gas and loss, and little recycling are due to the high efficiency in crystallization and isomerization and this in turn means low $p$-xylene production cost.

Investment cost and utility requirements are shown on Table 2. The cost of a Gulf Coast plant to produce $100,000 \mathrm{t} / \mathrm{yr}$ of $p$-xylene is estimated at $\$ 7.5$ million. This does not include superfractionation columns.

Since many factors must be taken into account it is rather difficult to generalize production cost of $p$-xylene. However, we have tried our best to estimate the cost of $p$-xylene production with utilities consumption given in Table 3. Our estimated $p$-xylene production cost is $4.5 \mathrm{\varepsilon} / \mathrm{lb}$. The cost of superfractionation is taken into account in the following way.

Reformate xylene is given at a price of 14.9 \&/gal. After superfractionation, ethylbenzene lean xylene would be valued at $19.0 \mathrm{e} / \mathrm{gal}$. Starting with $19.0 \mathrm{E} / \mathrm{gal}$ of ethylbenzene lean xylene, $p$ xylene can be produced at a cost of $4.5 \mathrm{e} / \mathrm{lb}$, including overhead and other expenses. The difference between the selling price and 4.5 $\mathrm{c} / \mathrm{lb}$ is a profit excluding tax. However, 4.5 e/lb docs not include a substantial delivery chargc. For cxample shipping $p$-xylene to Europe or Japan from Gulf Coast is not accounted for.
Table 2 Economics of Maruzen PX Process

\begin{tabular}{|c|c|c|}
\hline \multicolumn{3}{|c|}{$\begin{array}{l}\text { PX } 220.5 \times 10^{8} \mathrm{lb} / \mathrm{yr}(=100,000 \mathrm{t} / \mathrm{yr}) \\
\text { Battery Limits Capital Cost } \\
\text { \$ } 7.5 \text { Million Gulf Coast Base } \\
\text { (Excluding Super Fractionation) } \\
\text { Utilities }\end{array}$} \\
\hline $\begin{array}{l}\text { Utilities } \\
\text { PX Net }\end{array}$ & $\begin{array}{l}\text { Cooling Water } \\
\text { Electricity } \\
\text { Steam } \\
\text { Fuel } \\
\text { t Production Cost } \\
\end{array}$ & $\begin{array}{l}48 \times 10^{8} \mathrm{gal} / \mathrm{yr} \\
40 \times 10^{6} \mathrm{~kW} \cdot \mathrm{hr} / \mathrm{yr} \\
44 \times 10^{6} \mathrm{lb} / \mathrm{yr} \\
750 \times 10^{9} \mathrm{B.t.u} . / \mathrm{yr} \\
/ \mathrm{lb}\end{array}$ \\
\hline
\end{tabular}

Table 3 PX Net Production Cost

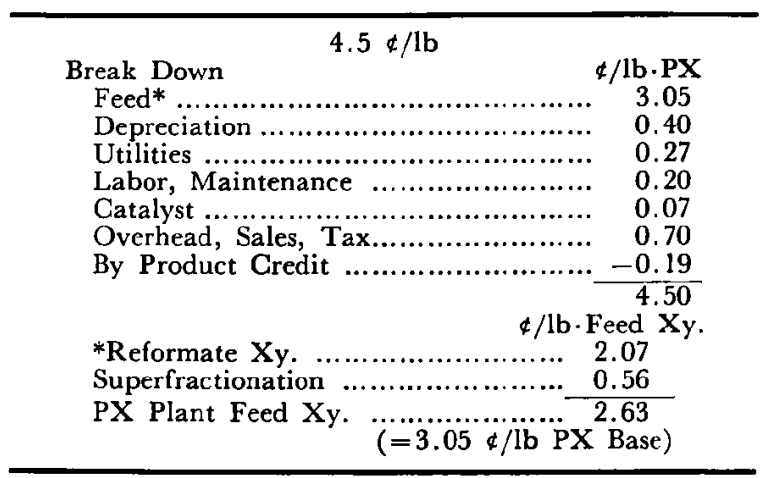

The most critical factor in $p$-xylene production is the cost of feedstock. In our example, the increase of $2 \% / \mathrm{gal}$ in the cost of reformate xylene makes $p$-xylene cost high by $7 \%$, that is, 0.32 $\varepsilon / \mathrm{lb}$ rise in $p$-xylene cost. Both 0 -xylene and ethylbenzene costs or credits also influence significantly on $p$-xylene cost. They can easily give a $p$-xylene price change from a quarter cent per pound to even a half cent per pound. A half-million-dollar battery-limit-investment variation influences the cost of $p$-xylene by only $0.05 \mathrm{c} / \mathrm{lb}$. But always decrease in the investment cost is certainly favorable to the pay out time.

\section{A View of Maruzen p-Xylene Process}

The most common feed stocks for $p$-xylene production are reformate and cracked oil. These feedstocks contain varieties of aromatics such as benzene, toluene, xylenes, ethylbenzene and heavier aromatics. These are many combinations of aromatic producing processes which provide different final products depending upon each market or demand. If only $p$-xylene is in need, Maruzen XIS process can treat reformate and produce $p$-xylene. No aromatics extraction and superfractionation units are required. If other aromatics such as benzene and toluene are to be produced together, the extraction and superfractionation units will treat reformate or cracked oil. 


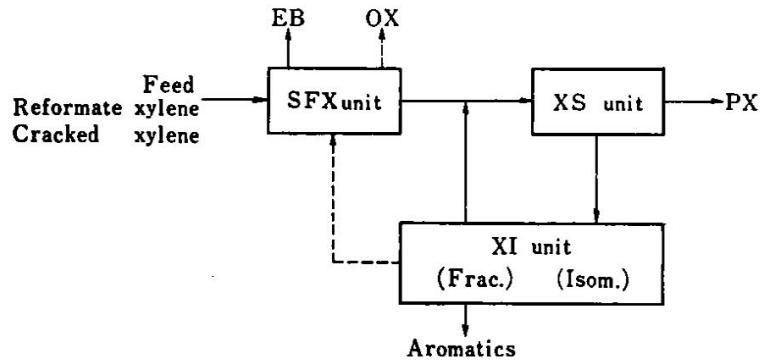

Fig. 14 Block Diagram of Combined PX, EB, OX Production

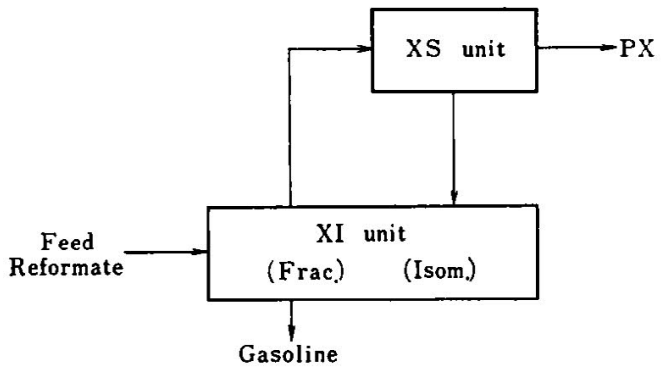

Fig. 15 Block Diagram of Sole PX Production

\subsection{Combined p-Xylene, Ethylbenzene and o-Xylene Production}

$P$-xylene, ethybenzene and 0 -xylene can be produced simultaneously through the combination of Maruzen Oil's SFX, XI and XS processes. Fig. 14 indicates that 0 -xylene production may be optional. Economic study warrants that chemical grade ethylbenzene production is economically favorable. However, if the market requires a large quantity of gasoline or solvent, regular fractionation columns rather than superfractionation columns may be sufficient, and reduce the investment and running costs. An extractive distillation is economical and sufficient in case of xylene production only, but a solvent extraction process must be used in case of benzene, toluene, and xylene production. An abundant supply of xylene may make it possible to use only the XS process on one through basis. However, judging from Japanese feed stock situations, it should be much more practical and economical to use combined XS and XI processes to obtain the high recovery of $p$-xylene on a limited supply of feed stock. It may be worth-while to point out that the overall yield of $p$-xylene is more important than the yield of recovery per pass as long as the feed stock is isomerized and recycled to the utmost. The high recovery per pass alone may not always sustain the preferable economics from the standpoint of $p$-xylene yield,

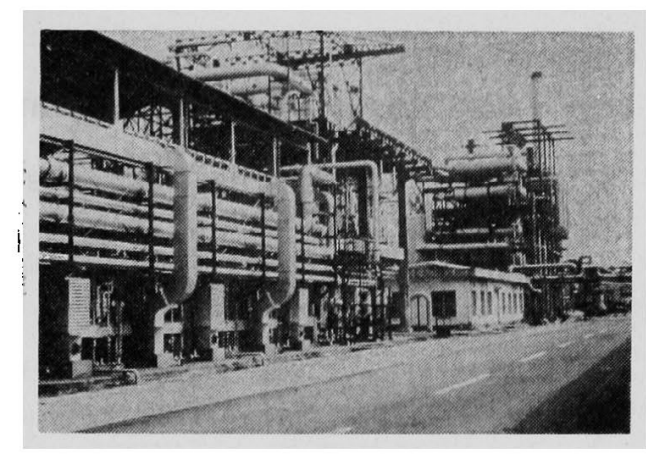

though an adsorption process generally gives higher recovery per pass than our process. Our experience and the economic evaluation support that the isomerization process generally controls the economics of $p$-xylene production. In other words, the selectivity and efficiency of the catalyst, which directly relates to the recycle volume, are the key factors in determining the overall investment and utilities consumption.

\subsection{Sole Production of $p$-Xylene}

In the case of sole production of $p$-xylene from reformate, it is possible and may be more economical to eliminate expensive extraction and superfractionation as shown Fig. 15. For this purpose, a reformate with 95 RON or higher may be distilled to make fractions with xylene rich and ethylbenzene lean. The remainder of the reformate is expected to have $93 \mathrm{RON}$ or higher and is used as a gasoline blending stock. Nonaromatics contained in the feed will be decomposed in the isomerization reactor and will not be accumulated to cause trouble in the operation. This scheme of $p$-xylene and gasoline blending stock production gives the lowest production $\cos ^{3)}$.

\section{Operating Experience}

Since 1956, the research for $p$-xylene separation and xylene isomerization has been going on continuously. The first commercial unit came on stream in 1960 at Maruzen Oil's Matsuyama Refinery. Maruzen $p$-xylene process is now being operated at the Matsuyama Petrochemical Company, Kuraray Petrochemical Company, and NEFTO CHIM Petrochemical Complex in Bulgaria.

\section{References}

1) Amemiya, T. et al., Bull. Japan Petrol. Inst., 1, 78 (1959).

2) Taylor, W. et al., J. Research Natl. Bur. Standard, 37, 95 (1946).

3) Nakamura, T., Process Handbook "XIS Process", Published by The Japan Petrol. Inst. (1973). 